\title{
Pengaruh Waktu Pengamatan Terhadap Ketelitian Posisi dalam Survei GPS
}

\author{
RINA ROSTIKA RAHMAN \\ Jurusan Teknik Geodesi, Institut Teknologi Nasional - Bandung \\ Email: rina.rostika.rahman@gmail.com
}

\begin{abstract}
ABSTRAK
Realitas pengalaman di lapangan menunjukkan bahwa data hasil pengamatan dari suatu survei GPS dari waktu ke waktu menghasilkan ketelitian posisi yang berbeda. Kenyataan tersebut menarik untuk dipelajari guna mengetahui waktu-waktu yang terbaik untuk melakukan pengamatan GPS. Dalam penelitian ini diteliti pengaruh waktu pengamatan terhadap ketelitian posisi dalam survei GPS, di mana waktu pengamatan dikelompokkan menjadi 5 (lima) bagian, yaitu: pagi, siang, sore, malam, dan subuh dengan selang waktu pengamatan 3 jam, 2 jam, dan 1 jam. Dari hasil hitungan diketahui bahwa waktu pengamatan yang terbaik untuk melakukan pengukuran pada survei GPS adalah siang hari sampai sore hari, yaitu sekitar pukul 11.00-18.00 WIB.
\end{abstract}

Kata kunci: GPS RTK, ETS, posisi titik, ekstraterestrial.

\begin{abstract}
Reality of experience in the field indicates that the measurement data of GPS survey from time to time result in different position accuracy. It is interesting to study to know the best times for perform GPS observations. This research examined the influence of observing time to the position accuracy of GPS survey by which time observations are grouped into 5 (five) parts: morning, afternoon, evening, night, and dawn at observation intervals of 3 hours, 2 hours, and 1 hours. From the obtained result it is known that the best time to take the GPS survey measurements is during afternoon until evening at around $11.00-18.00 \mathrm{pm}$.
\end{abstract}

Keywords: GPS RTK, ETS, point position, extraterrestrial. 


\section{PENDAHULUAN}

Ketelitian data hasil pengukuran dari survei GPS pada dasarnya dipengaruhi oleh tiga faktor yaitu jenis data yang digunakan (pseudorange atau fase), kualitas dari receiver GPS yang digunakan, dan bias yang disebabkan adanya gangguan pada media atmosfer saat gelombang elektromagnetik merambat dari satelit ke receiver [Abidin, 2001]. Gangguan pada media atmosfer dapat terjadi di antaranya karena adanya fenomena alam yang menyebabkan stabilitas kandungan elektron terganggu dari waktu ke waktu, sehingga dapat menghambat kecepatan perambatan gelombang elektromagnetik pada saat melewati media perantara. Realitas pengalaman di lapangan menunjukkan bahwa data hasil pengamatan dari hasil suatu survei GPS dari waktu ke waktu menghasilkan ketelitian posisi yang berbeda. Kenyataan tersebut menarik untuk dipelajari guna mengetahui waktu-waktu yang terbaik melakukan pengukuran GPS untuk mendapatkan ketelitian posisi yang terbaik. Dalam penelitian ini akan diteliti pengaruh waktu pengamatan terhadap ketelitian posisi dalam survei GPS, di mana waktu pengamatan dikelompokkan menjadi lima bagian, yaitu: pagi, siang, sore, malam, dan subuh.

Ketelitian data yang diperoleh survei GPS secara umum akan bergantung pada waktu dan lamanya pengamatan. Pemilihan waktu pada pengamatan survei GPS berguna untuk memberikan kualitas data dengan tingkat ketelitian tertentu yang diperoleh dari hasil survei GPS. Permasalahan yang dapat diajukan adalah: "Bagaimana pengaruh waktu pengamatan terhadap ketelitan posisi yang dihasilkan dari hasil survei GPS?". Tujuan dari penelitian ini adalah untuk mempelajari keterkaitan antara waktu pengamatan terhadap ketelitian posisi titik yang dihasilkan dari survei GPS. Atmosfer yang merupakan media rambat gelombang elektromagnetik data diasumsikan dalam keadaan stabil, pengelompokkan waktu didasarkan pendekatan kondisi temperatur udara yang terjadi di suatu tempat, Data yang digunakan adalah data hasil pengamatan GPS menggunakan receiver HITARGET HD8200X single frequency (L1) dengan format RINEX , analisis ketelitian berdasarkan ketelitian koordinat yang diwakili oleh harga setengah sumbu panjang dari elips kesalahan absolut.

\section{METODOLOGI PENELITIAN}

Pengamatan dilaksanakan di empat titik dengan sebaran titik-titik berada di wilayah Itenas, Antapani, Awiligar, dan Cilengkrang-Ujung berung. Sketsa geometri jaring yang digunakan dalam penelitian dapat dilihat pada Gambar 1.

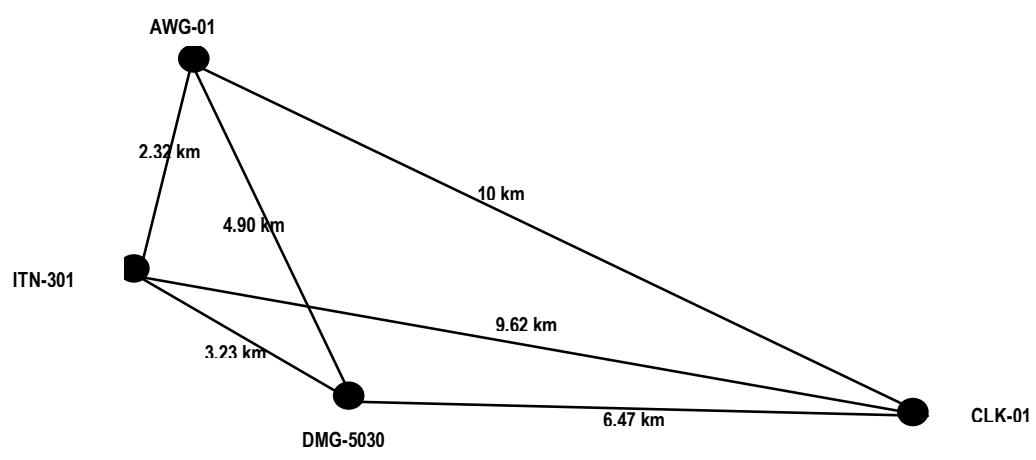

Gambar 1. Sketsa Geometri Jaring 
Data yang digunakan adalah data hasil pengamatan GPS menggunakan receiver HI-TARGET HD8200X single frequency (L1) dengan format RINEX. Metode pengamatan yang digunakan dalam pengambilan data adalah metode diferensial statik. Proses pengolahan data dapat dilihat pada Gambar 2.

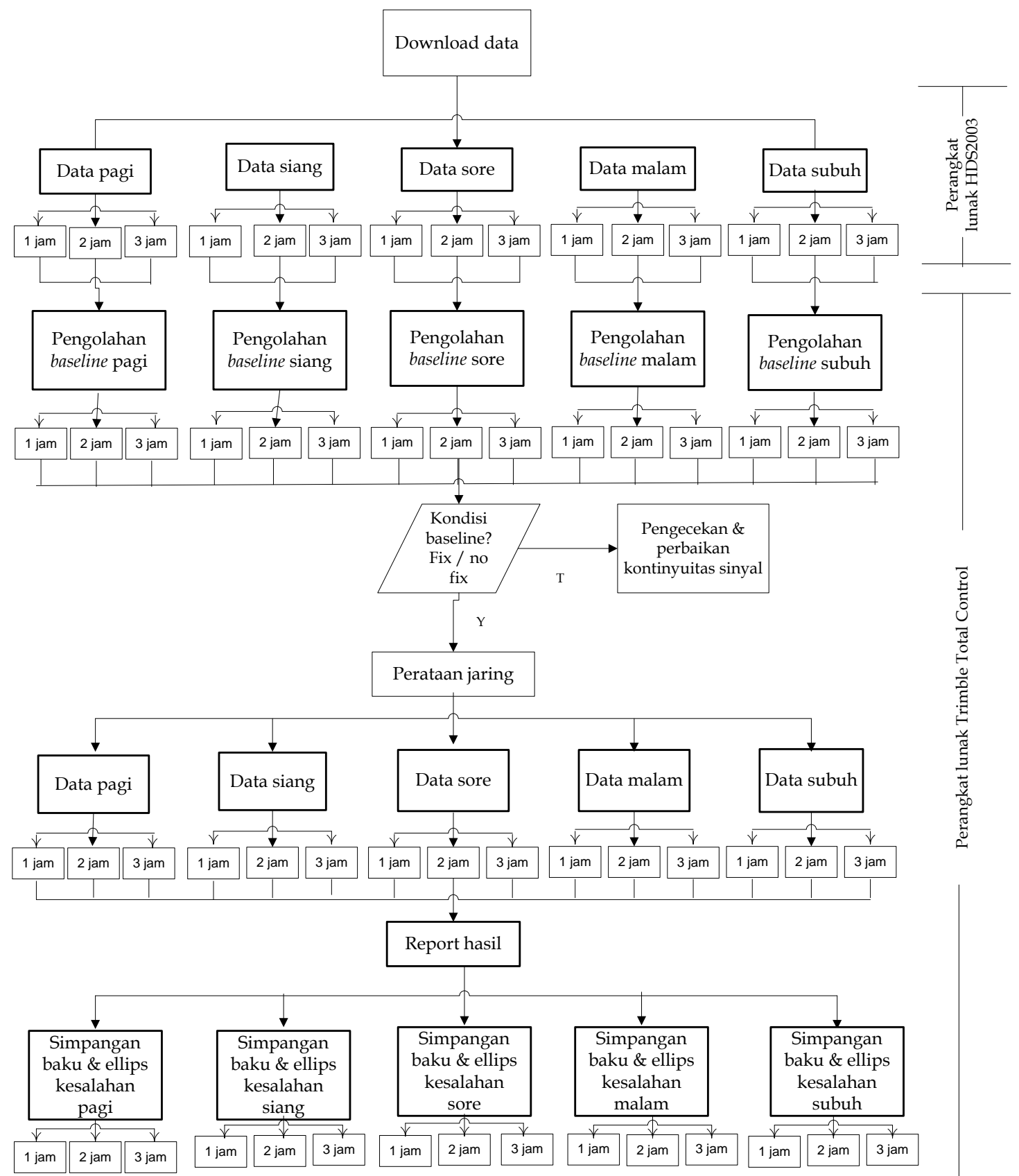

Gambar 2. Pengolahan Data 


\section{HASIL DAN ANALISIS}

\subsection{Hasil}

Hasil akhir dari penelitian ini adalah data yang menunjukkan ketelitian posisi titik yang diwakili oleh simpangan baku $\left(\sigma_{h}\right)$, serta nilai elips kesalahan yang diperoleh dari hasil hitungan pengamatan GPS pada pagi, siang, sore, malam, dan subuh. Hasil hitungan posisi titik dihitung menggunakan data pengamatan pagi, siang, sore, malam, dan subuh dengan rentang waktu pengamatan selama 1 jam, 2 jam, dan 3 jam. Hasil hitungan posisi horisontal dan vertikal ditampilkan pada Tabel 1 dan 2 berikut.

\section{Tabel 1. Hasil Hitungan Posisi Horisontal}

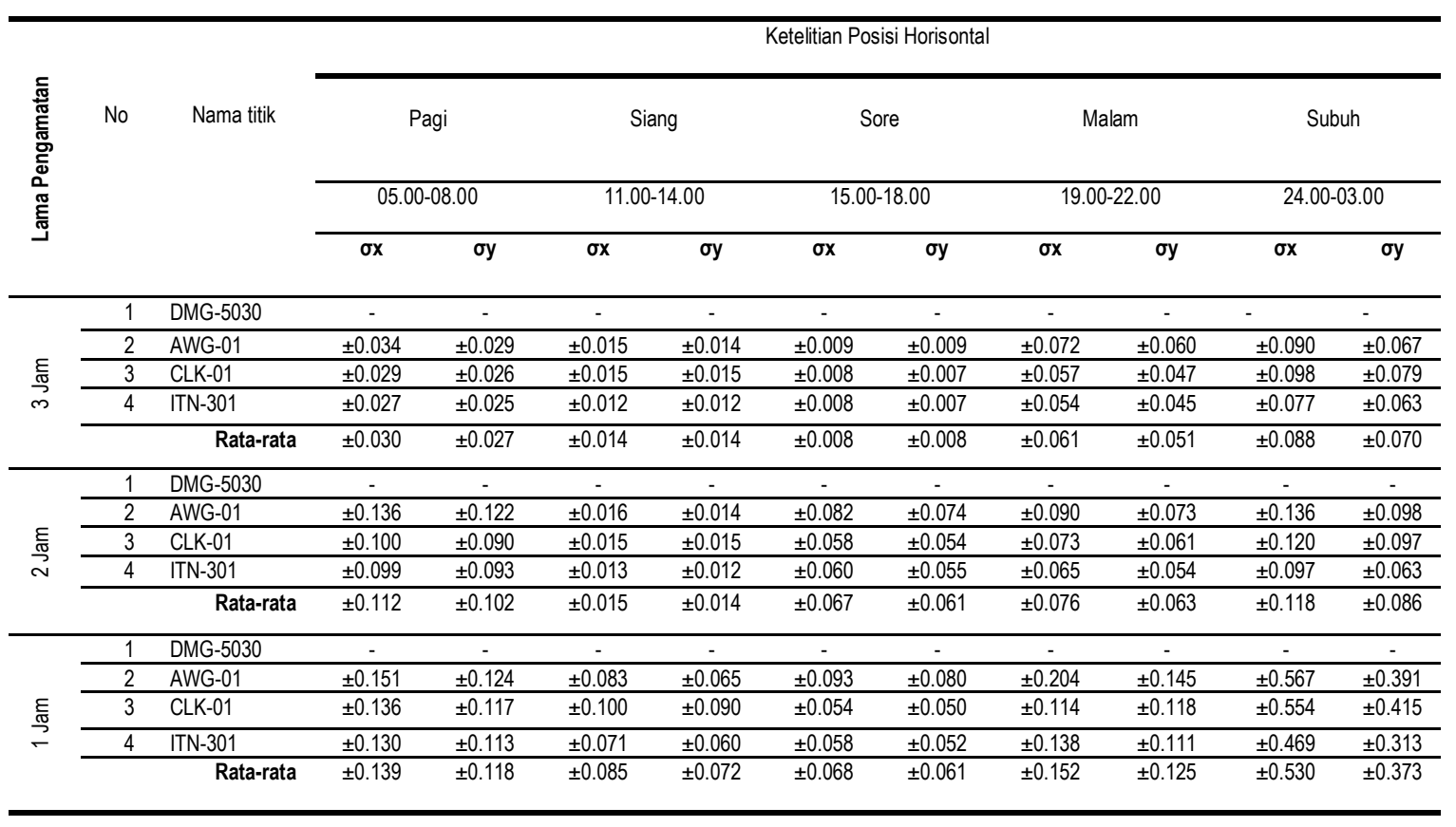

Tabel 2. Hasil Hitungan Posisi Vertikal

\begin{tabular}{|c|c|c|c|c|c|c|c|}
\hline \multirow{2}{*}{ 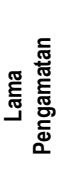 } & \multirow[b]{2}{*}{ No } & \multirow[b]{2}{*}{ Nama titik } & \multicolumn{5}{|c|}{ Ketelitian Posisi Vertikal } \\
\hline & & & $\begin{array}{c}\text { Pagi } \\
\sigma_{\mathrm{h}}\end{array}$ & $\begin{array}{c}\text { Siang } \\
\sigma_{\mathrm{h}}\end{array}$ & $\begin{array}{c}\text { Sore } \\
\sigma_{\mathrm{h}}\end{array}$ & $\begin{array}{c}\text { Malam } \\
\sigma_{\mathrm{h}}\end{array}$ & $\begin{array}{c}\text { Subuh } \\
\sigma_{\mathrm{h}}\end{array}$ \\
\hline \multirow{5}{*}{$\underset{m}{\stackrel{E}{\mathbb{T}}}$} & 1 & DMG-5030 & - & - & - & & \\
\hline & 2 & AWG-01 & \pm 0.044 & \pm 0.021 & \pm 0.012 & \pm 0.082 & \pm 0.094 \\
\hline & 3 & CLK-01 & \pm 0.036 & \pm 0.021 & \pm 0.011 & \pm 0.065 & \pm 0.113 \\
\hline & 4 & ITN-301 & \pm 0.036 & \pm 0.017 & \pm 0.010 & \pm 0.057 & \pm 0.078 \\
\hline & & ta-rata & \pm 0.039 & \pm 0.020 & \pm 0.011 & \pm 0.068 & \pm 0.095 \\
\hline \multirow{5}{*}{$\underset{\sim}{\stackrel{E}{\mathbb{N}}}$} & 1 & DMG-5030 & - & - & - & - & - \\
\hline & 2 & AWG-01 & \pm 0.179 & \pm 0.023 & \pm 0.136 & \pm 0.105 & \pm 0.126 \\
\hline & 3 & CLK-01 & \pm 0.134 & \pm 0.022 & \pm 0.089 & \pm 0.083 & \pm 0.139 \\
\hline & 4 & ITN-301 & \pm 0.132 & \pm 0.017 & \pm 0.091 & \pm 0.069 & \pm 0.097 \\
\hline & & ta-rata & \pm 0.148 & \pm 0.021 & \pm 0.105 & \pm 0.086 & \pm 0.121 \\
\hline \multirow{4}{*}{ 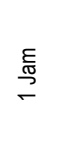 } & 1 & DMG-5030 & - & - & - & - & \\
\hline & 2 & AWG-01 & \pm 0.153 & \pm 0.095 & \pm 0.143 & \pm 0.260 & \pm 0.634 \\
\hline & 3 & CLK-01 & \pm 0.160 & \pm 0.131 & \pm 0.086 & \pm 0.168 & \pm 0.662 \\
\hline & 4 & ITN-301 & \pm 0.149 & \pm 0.085 & \pm 0.086 & \pm 0.146 & \pm 0.466 \\
\hline
\end{tabular}




\begin{tabular}{llllll}
\hline Rata-rata & \pm 0.154 & \pm 0.104 & \pm 0.105 & \pm 0.191 & 0.587 \\
\hline
\end{tabular}

Harga setengah sumbu panjang elips kesalahan ditampilkan pada Tabel 3, grafik harga setengah sumbu panjang elips kesalahan dan grafik simpangan baku tinggi dapat dilihat pada Gambar 3 dan 4.

Tabel 3. Hasil Hitungan Harga Setengah Sumbu Panjang Elips Kesalahan

\begin{tabular}{|c|c|c|c|c|c|c|c|c|c|c|c|c|}
\hline \multirow{3}{*}{ 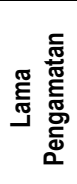 } & \multirow{3}{*}{$\begin{array}{c}\text { No } \\
\text {. }\end{array}$} & \multirow{3}{*}{ Nama titik } & \multicolumn{10}{|c|}{ Harga setengah sumbu panjang elips kesalahan } \\
\hline & & & \multicolumn{2}{|c|}{ pagi } & \multicolumn{2}{|c|}{ siang } & \multicolumn{2}{|c|}{ sore } & \multicolumn{2}{|c|}{ malam } & \multicolumn{2}{|c|}{ subuh } \\
\hline & & & $\sigma u$ & $\mathrm{t}$ & $\sigma \cup$ & $\mathrm{t}$ & $\sigma \cup$ & $\mathrm{t}$ & $\sigma \cup$ & $\mathrm{t}$ & $\sigma \cup$ & $\mathrm{t}$ \\
\hline \multirow{5}{*}{$\begin{array}{c}\frac{E}{\text { D }} \\
\text { m }\end{array}$} & 1 & DMG-5030 & - & - & - & - & - & - & - & - & - & - \\
\hline & 2 & AWG-01 & \pm 0.034 & $77.7^{\circ}$ & \pm 0.015 & $\begin{array}{c}- \\
74.2^{\circ}\end{array}$ & \pm 0.009 & $\begin{array}{c}- \\
46.8^{\circ}\end{array}$ & \pm 0.073 & $75.8^{\circ}$ & \pm 0.091 & $77.5^{\circ}$ \\
\hline & 3 & CLK-01 & \pm 0.029 & $89.8^{\circ}$ & \pm 0.015 & $47.7^{\circ}$ & \pm 0.008 & $69.9^{\circ}$ & \pm 0.057 & $87^{-}$ & \pm 0.099 & $73.5^{\circ}$ \\
\hline & 4 & ITN-301 & \pm 0.027 & $84.1^{\circ}$ & \pm 0.013 & $62.1^{\circ}$ & \pm 0.008 & $\begin{array}{c}- \\
67.0^{\circ} \\
\end{array}$ & \pm 0.054 & $\begin{array}{c}- \\
83.6^{\circ}\end{array}$ & \pm 0.077 & $81.5^{\circ}$ \\
\hline & & Rata-rata & \pm 0.030 & & \pm 0.014 & & \pm 0.008 & & \pm 0.061 & & \pm 0.089 & \\
\hline \multirow{5}{*}{$\frac{E}{\stackrel{E}{D}}$} & 1 & DMG-5030 & - & - & - & - & - & - & - & - & - & - \\
\hline & 2 & AWG-01 & \pm 0.149 & $54.8^{\circ}$ & \pm 0.016 & $82.8^{\circ}$ & \pm 0.090 & $55.3^{\circ}$ & \pm 0.090 & $89.7^{\circ}$ & \pm 0.136 & $86.5^{\circ}$ \\
\hline & 3 & CLK-01 & \pm 0.101 & $78.1^{\circ}$ & \pm 0.016 & $45.0^{\circ}$ & \pm 0.062 & $55.7^{\circ}$ & \pm 0.073 & $85.5^{\circ}$ & \pm 0.123 & $72.2^{\circ}$ \\
\hline & 4 & ITN-301 & \pm 0.100 & $69.6^{\circ}$ & \pm 0.013 & $62.7^{\circ}$ & \pm 0.062 & $63.5^{\circ}$ & \pm 0.066 & $80.4^{\circ}$ & \pm 0.097 & $83.3^{\circ}$ \\
\hline & & Rata-rata & \pm 0.117 & & \pm 0.015 & & \pm 0.071 & & \pm 0.076 & & \pm 0.119 & \\
\hline \multirow{5}{*}{ 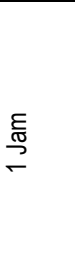 } & 1 & DMG-5030 & - & - & - & - & - & - & - & - & - & - \\
\hline & 2 & AWG-01 & \pm 0.152 & $82.5^{\circ}$ & \pm 0.085 & $70.5^{\circ}$ & \pm 0.104 & $55.6^{\circ}$ & \pm 0.207 & $77.0^{\circ}$ & \pm 0.571 & $80.7^{\circ}$ \\
\hline & 3 & CLK-01 & \pm 0.136 & $81.8^{\circ}$ & \pm 0.101 & $75.4^{\circ}$ & \pm 0.057 & $56.2^{\circ}$ & \pm 0.144 & $87.5^{\circ}$ & \pm 0.563 & $75.1^{\circ}$ \\
\hline & 4 & ITN-301 & \pm 0.130 & $82.9^{\circ}$ & \pm 0.071 & $75.7^{\circ}$ & \pm 0.059 & $66.8^{\circ}$ & \pm 0.138 & $83.2^{\circ}$ & \pm 0.472 & $\begin{array}{c} \\
81.4^{\circ} \\
\end{array}$ \\
\hline & & Rata-rata & \pm 0.139 & & \pm 0.086 & & \pm 0.073 & & \pm 0.163 & & \pm 0.535 & \\
\hline
\end{tabular}

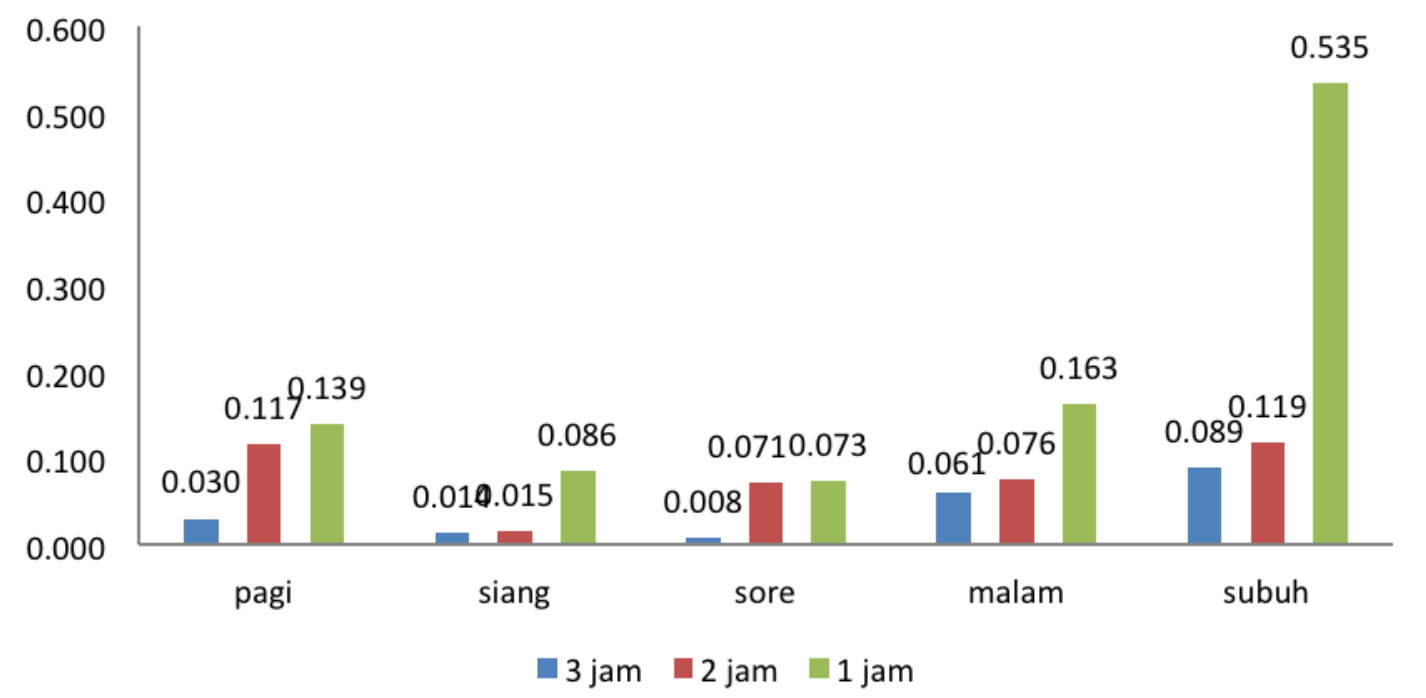

Gambar 3. Grafik Harga Setengah Sumbu Panjang dari Elips Kesalahan 


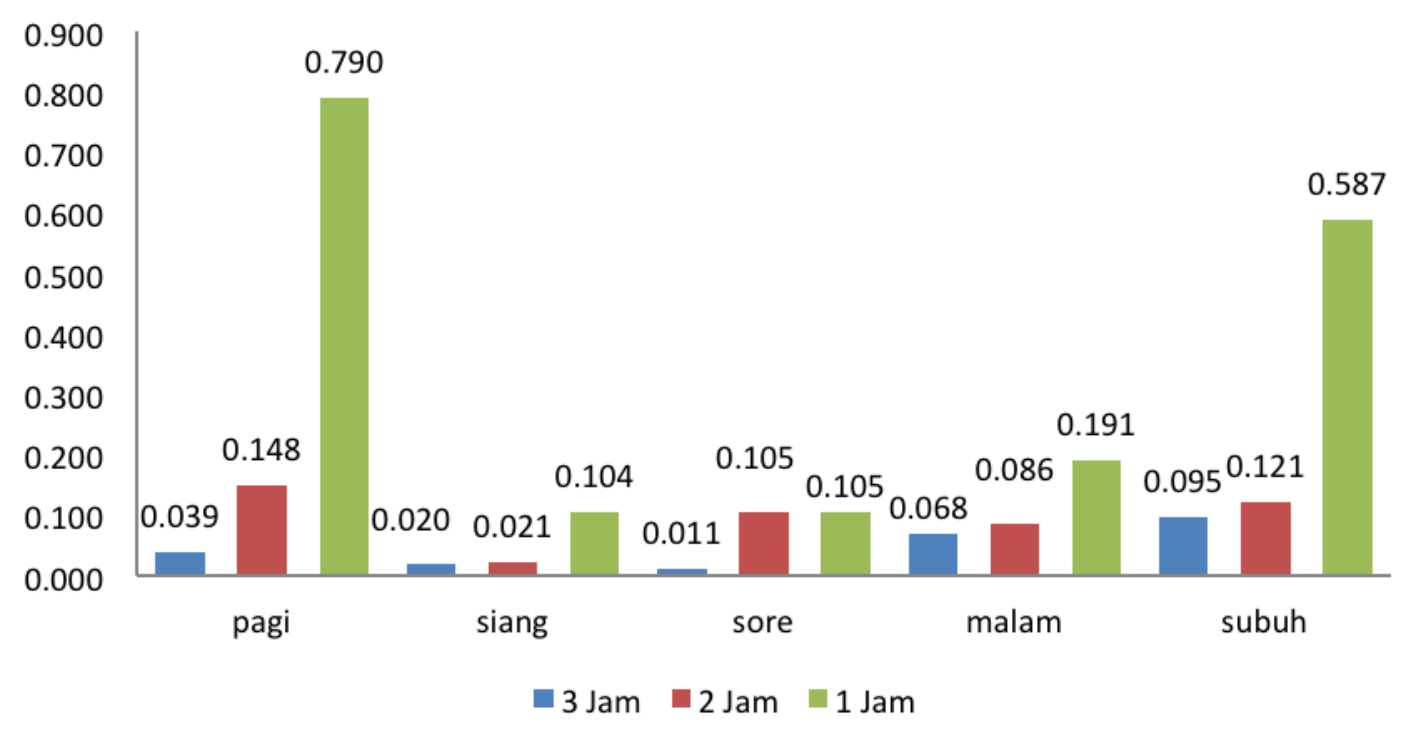

Gambar 4. Grafik Simpangan Baku Tinggi

\subsection{Analisis}

Baseline yang digunakan dalam penelitian ini merupakan baseline pendek ( \pm 10 $\mathrm{km}$ ) sehingga kondisi atmosfer di lokasi pengamatan dapat dianggap sama, dan pengaruh bias atmosfer di lokasi pengamatan diasumsikan sama, baseline yang diolah adalah data baseline bebas (non trivial), dengan waktu pengamatan untuk setiap baseline 3 jam, 2 jam, dan 1 jam dengan jumlah satelit yang terekam ratarata sebanyak 13 satelit. Proses yang dilakukan pada pengolahan baseline yaitu, perbaikan kontinyuitas data dengan melakukan pemotongan sinyal satelit yang terputus-putus saat pengamatan. Pemotongan sinyal pada beberapa data pengamatan dilakukan untuk menghilangkan pengaruh noise yang terjadi pada sinyal yang terekam untuk masing-masing satelit. Proses hitung perataan jaringan dilakukan bila data telah mempunyai ketelitian yang baik maka dapat dilakukan proses perataan jaring, data dikategorikan baik apabila garis pada setiap baseline berwarna hijau.

Akan ditinjau besarnya ketelitian posisi horisontal yang diwakili oleh harga setengah sumbu panjang $\left(\sigma_{u}\right)$ dari elips kesalahan yang dimiliki oleh masing-masing titik seperti pada Tabel 1 dan 3 serta Gambar 3. Berdasarkan Tabel 1 dan 3 serta Gambar 3 dapat dianalisis hal-hal terkait sebagai berikut: (1) Ketelitian posisi horisontal titik hasil perhitungan menggunakan data pengamatan selama 3 jam yang diwakili oleh data siang dan sore hari memberikan hasil yang paling teliti dibandingkan dengan hasil pengamatan pada pagi, malam, dan subuh dengan ketelitian posisi horisontal rata-rata $\pm 14 \mathrm{~cm}$ dan $\pm 8 \mathrm{~cm}$; (2) Ketelitian posisi horisontal titik hasil perhitungan menggunakan data pengamatan selama 2 jam yang diwakili oleh data siang hari memberikan hasil yang paling teliti dibandingkan dengan hasil pengamatan pada pagi, sore, malam, dan subuh dengan ketelitian posisi horisontal rata-rata $\pm 15 \mathrm{~cm}$; (3) Ketelitian posisi horisontal titik hasil 
perhitungan menggunakan data pengamatan selama 1 jam yang diwakili oleh data siang dan sore hari memberikan hasil yang paling teliti dibandingkan dengan hasil pengamatan pada pagi, malam dan subuh dengan ketelitian posisi horisontal ratarata $\pm 86 \mathrm{~cm}$ dan $\pm 73 \mathrm{~cm}$.

Analisis pengaruh kelima model pengamatan terhadap ketelitian posisi vertikal, rekapitulasi besarnya simpangan baku rata-rata posisi vertikal untuk masingmasing hitungan yang ditampilkan berdasarkan Tabel 2 dan Gambar 4 dapat dianalisis hal-hal terkait sebagai berikut: (1) Ketelitian posisi vertikal titik hasil perhitungan menggunakan data pengamatan 3 jam yang diwakili oleh data siang dan sore hari memberikan hasil yang paling teliti dibandingkan dengan hasil pengamatan pagi, malam, dan subuh dengan posisi vertikal rata-rata $\pm 20 \mathrm{~cm}$ dan $\pm 11 \mathrm{~cm}$; (2) Ketelitian posisi vertikal titik hasil perhitungan menggunakan data pengamatan 2 jam yang diwakili oleh data siang hari memberikan hasil yang paling teliti dibandingkan dengan hasil pengamatan pagi, sore, malam, dan subuh dengan posisi vertikal rata-rata $\pm 21 \mathrm{~cm}$; (3) Ketelitian posisi vertikal titik hasil perhitungan menggunakan data pengamatan 1 jam yang diwakili oleh data siang hari memberikan hasil yang paling teliti dibandingkan dengan hasil pengamatan pagi, siang, malam, dan subuh dengan posisi vertikal rata-rata $\pm 104 \mathrm{~cm}$.

\section{KESIMPULAN}

Berdasarkan hasil analisis dari data penelitian hasil pengamatan GPS satu frekuensi (L1), dapat disimpulkan bahwa waktu pengamatan pada survei GPS berpengaruh terhadap ketelitian posisi yang dihasilkan. Waktu pengamatan yang terbaik untuk melakukan pengukuran pada survei GPS adalah siang hari sampai dengan sore hari yaitu sekitar jam 11.00-18.00 WIB. Berdasarkan data hasil pengamatan menggunakan GPS single frequency (L1) untuk baseline pendek (kurang dari 10 $\mathrm{km}$ ) dengan waktu pengamatan selama 3 jam, ketelitian rata-rata yang dihasilkan mencapai lebih dari $5 \mathrm{~cm}$. Dengan waktu pengamatan selama 2 jam, ketelitian ratarata yang dihasilkan mencapai $10 \mathrm{~cm}$. Dengan waktu pengamatan selama 1 jam, ketelitian rata-rata yang dihasilkan mencapai kurang dari $20 \mathrm{~cm}$. Ketelitian posisi yang dihasilkan pada pengamatan yang dilakukan selama waktu subuh (jam 24.0003.00) menghasilkan nilai yang jelek (lebih dari $50 \mathrm{~cm}$ ).

\section{UCAPAN TERIMA KASIH}

Penulis mengucapkan terima kasih kepada PT Mysurv Penta Benua yang telah meminjamkan alat receiver HI-TARGET HD8200X single frequency (L1) untuk keperluan penelitian ini.

\section{DAFTAR PUSTAKA}

Abidin, H.Z. 2000. Penentuan Posisi Dengan GPS dan Aplikasinya. Jakarta: P.T. Pradnya Paramita. Edisi Kedua. ISBN 979-408-377-1.268 pp. 